NASA/TM-2011-216960

Development and Implementation of a ModelDriven Envelope Protection System for In-Flight Ice Contamination

David R. Gingras and Billy P. Barnhart

Bihrle Applied Research, Inc., Hampton, Virginia

Richard J. Ranaudo and Borja Martos

University of Tennessee Space Institute, Tullahoma, Tennessee

Thomas P. Ratvasky

Glenn Research Center, Cleveland, Ohio

Eugene Morelli

Langley Research Center, Hampton, Virginia 


\section{NASA STI Program . . . in Profile}

Since its founding, NASA has been dedicated to the advancement of aeronautics and space science. The NASA Scientific and Technical Information (STI) program plays a key part in helping NASA maintain this important role.

The NASA STI Program operates under the auspices of the Agency Chief Information Officer. It collects, organizes, provides for archiving, and disseminates NASA's STI. The NASA STI program provides access to the NASA Aeronautics and Space Database and its public interface, the NASA Technical Reports Server, thus providing one of the largest collections of aeronautical and space science STI in the world. Results are published in both non-NASA channels and by NASA in the NASA STI Report Series, which includes the following report types:

- TECHNICAL PUBLICATION. Reports of completed research or a major significant phase of research that present the results of NASA programs and include extensive data or theoretical analysis. Includes compilations of significant scientific and technical data and information deemed to be of continuing reference value. NASA counterpart of peer-reviewed formal professional papers but has less stringent limitations on manuscript length and extent of graphic presentations.

- TECHNICAL MEMORANDUM. Scientific and technical findings that are preliminary or of specialized interest, e.g., quick release reports, working papers, and bibliographies that contain minimal annotation. Does not contain extensive analysis.

- CONTRACTOR REPORT. Scientific and technical findings by NASA-sponsored contractors and grantees.
- CONFERENCE PUBLICATION. Collected papers from scientific and technical conferences, symposia, seminars, or other meetings sponsored or cosponsored by NASA.

- SPECIAL PUBLICATION. Scientific, technical, or historical information from NASA programs, projects, and missions, often concerned with subjects having substantial public interest.

- TECHNICAL TRANSLATION. Englishlanguage translations of foreign scientific and technical material pertinent to NASA's mission.

Specialized services also include creating custom thesauri, building customized databases, organizing and publishing research results.

For more information about the NASA STI program, see the following:

- Access the NASA STI program home page at http://www.sti.nasa.gov

- E-mail your question via the Internet to help@ sti.nasa.gov

- Fax your question to the NASA STI Help Desk at $443-757-5803$

- Telephone the NASA STI Help Desk at 443-757-5802

- Write to: NASA Center for AeroSpace Information (CASI) 7115 Standard Drive Hanover, MD 21076-1320 
NASA/TM-2011-216960

AIAA-2010-8141

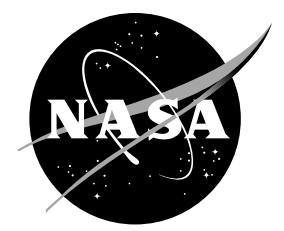

\section{Development and Implementation of a Model- Driven Envelope Protection System for In-Flight Ice Contamination}

David R. Gingras and Billy P. Barnhart

Bihrle Applied Research, Inc., Hampton, Virginia

Richard J. Ranaudo and Borja Martos

University of Tennessee Space Institute, Tullahoma, Tennessee

Thomas P. Ratvasky

Glenn Research Center, Cleveland, Ohio

Eugene Morelli

Langley Research Center, Hampton, Virginia

Prepared for the

Guidance, Navigation, and Control Conference

sponsored by the American Institute of Aeronautics and Astronautics

Toronto, Ontario, Canada, August 2-5, 2010

National Aeronautics and

Space Administration

Glenn Research Center

Cleveland, Ohio 44135 


\section{Acknowledgments}

The authors would like to thank the NASA Aviation Safety Program's Integrated Vehicle Health Management Project for their sponsorship of the effort reported herein.

Trade names and trademarks are used in this report for identification only. Their usage does not constitute an official endorsement, either expressed or implied, by the National Aeronautics and Space Administration.

Level of Review: This material has been technically reviewed by technical management.

Available from

NASA Center for Aerospace Information 7115 Standard Drive

Hanover, MD 21076-1320
National Technical Information Service 5301 Shawnee Road Alexandria, VA 22312

Available electronically at http://www.sti.nasa.gov 


\title{
Development and Implementation of a Model-Driven Envelope Protection System for In-Flight Ice Contamination
}

\author{
David R. Gingras and Billy P. Barnhart \\ Bihrle Applied Research, Inc. \\ Hampton, Virginia 23666 \\ Richard J. Ranaudo and Borja Martos \\ University of Tennessee Space Institute \\ Tullahoma, Tennessee 37388 \\ Thomas P. Ratvasky \\ National Aeronautics and Space Administration \\ Glenn Research Center \\ Cleveland, Ohio 44135 \\ Eugene Morelli \\ National Aeronautics and Space Administration \\ Langley Research Center \\ Hampton, Virginia 23681-2199
}

\begin{abstract}
Fatal loss-of-control (LOC) accidents have been directly related to in-flight airframe icing. The prototype system presented in this paper directly addresses the need for real-time onboard envelope protection in icing conditions. The combinations of a-priori information and real-time aerodynamic estimations are shown to provide sufficient input for determining safe limits of the flight envelope during in-flight icing encounters. The Icing Contamination Envelope Protection (ICEPro) system has been designed and implemented to identify degradations in airplane performance and flying qualities resulting from ice contamination and provide safe flight-envelope cues to the pilot. Components of ICEPro are described and results from preliminary tests are presented.
\end{abstract}

\section{Introduction}

The University of Tennessee Space Institute (UTSI) in partnership with Bihrle Applied Research (BAR) has completed a 3-year cooperative research effort with NASA in response to the NASA Research Announcement (NRA) NNH06ZEA001N under Appendix B of the Aviation Safety Program. A prototype Icing Contamination Envelope Protection (ICEPro) system was developed to meet the objectives defined under the Integrated Vehicle Health Management (IVHM) Project, topic IVHM 3.1, Environmental Hazards, which are caused by the "Effects of Icing on Aircraft State". This paper presents the results of this research, which focuses on the concept, design, development, implementation, and evaluation of the real-time vehicle state assessment system.

\section{Background}

Airframe icing continues to be a threat to aviation safety across the globe. Icing-induced loss of control incidents and accidents have occurred and continue to occur on all classes of aircraft-from general aviation airplanes (Ref. 1) and business jets (Ref. 2), to transport category aircraft (Refs. 3 to 8 ) NASA recently published results from statistical analyses that examined trends of icing-related events over a 16-year period (1988 to 2003) (Ref. 9). The study showed that nearly 9-percent of all fatal 
accidents from Part 121 and Scheduled Part 135 operations occurred while flying in icing conditions. During an icing encounter, flight characteristics can be severely degraded if hazardous ice formations accrete on wings and tail surfaces due to improper use of the ice protection systems (IPS), IPS failure, or encountering "exceedance conditions". Exceedance conditions occur when an aircraft is exposed to icing conditions outside of the FAR 25 Appendix C criteria, for which the aircraft is certificated. This is often referred to as Super-cooled Large Droplet (SLD) icing conditions. Each of these situations has caused serious aircraft handling problems and resulted in stall and/or departure from controlled flight.

One notable accident referenced above involved an ATR 72 that flew through SLD icing conditions near Roselawn, Indiana on October 31, 1994. Even with the IPS operating normally, the aircraft experienced a roll control anomaly that led to the loss of control and impact into the ground. This accident and others since then have led to numerous safety recommendations from the National Transportation Safety Board (NTSB) (Refs. 10 and 11) and the Commercial Aviation Safety Team (CAST) (Ref. 12) and motivated research activities within NASA and the FAA. One NASA sponsored activity called the Smart Icing Systems was led by the University of Illinois, Urbana-Champaign (UIUC). The Smart Icing Systems took a systems level approach to detecting icing conditions, operating ice protection systems and alerting the flight crew to the status of the aircraft (Ref. 13).

This work laid the foundation to continue research to develop and improve real-time state assessment methods for vehicle health management with application to detecting and mitigating icing hazards. This effort was performed under a NRA with the UTSI and BAR, in collaboration with the NASA Glenn and NASA Langley Research Centers. The development of real-time state assessment methods and their use in providing flight and control limit information to the pilot through cues and messaging on his displays are an essential aspect of this research effort.

The final developed Icing Contamination Envelope Protection (ICEPro) system was evaluated by a group of pilots to assess their performance using the provided cues and messages while performing a typical IFR approach and landing compared to a control group who did not have the cues.

Details of the design, implementation, and verification process of this unique system, as well as a synopsis of the piloted evaluations and conclusions are contained herein

\section{ICEPro Concept}

The ICEPro concept is best summarized by the hypothesis posed by the development team during preliminary stages of the design process.

By the real-time processing of measured state and control information, estimates of stability and control can be used in conjunction with a knowledge base, comprised of a-priori data, to provide pilots with envelope-limiting cueing in order to avoid loss-of-control or adverse conditions resulting from in-flight icing.

The ICEPro system was designed and implemented to identify degradations in airplane performance and flying qualities resulting from ice contamination and to provide safe flight-envelope cues to the pilot. This is accomplished by the real-time processing of measured state and control information to provide estimates of stability and control characteristics that are then used in conjunction with a knowledge base, comprised of a-priori data, to provide pilots with envelope-limiting cueing in order to avoid loss-ofcontrol or adverse conditions resulting from in-flight icing.

The ICEPro concept relies on the actions of a proficient pilot responding to appropriate cueing and information on the primary and secondary displays in the cockpit. It is believed that, with these cues, the pilot can make informed decisions as to how the airplane is being flown. The ICEPro concept provides envelope protection by issuing advisories, cautions, and warnings in the form of airspeed limits, angle of attack limits, flap position limits, and control effectiveness status. The indications are intended to be consistent with typical advisories and warnings that appear on flight displays such that they are intuitive and effective. Figure 1 provides a graphic illustrating the cueing that is used in the system. 


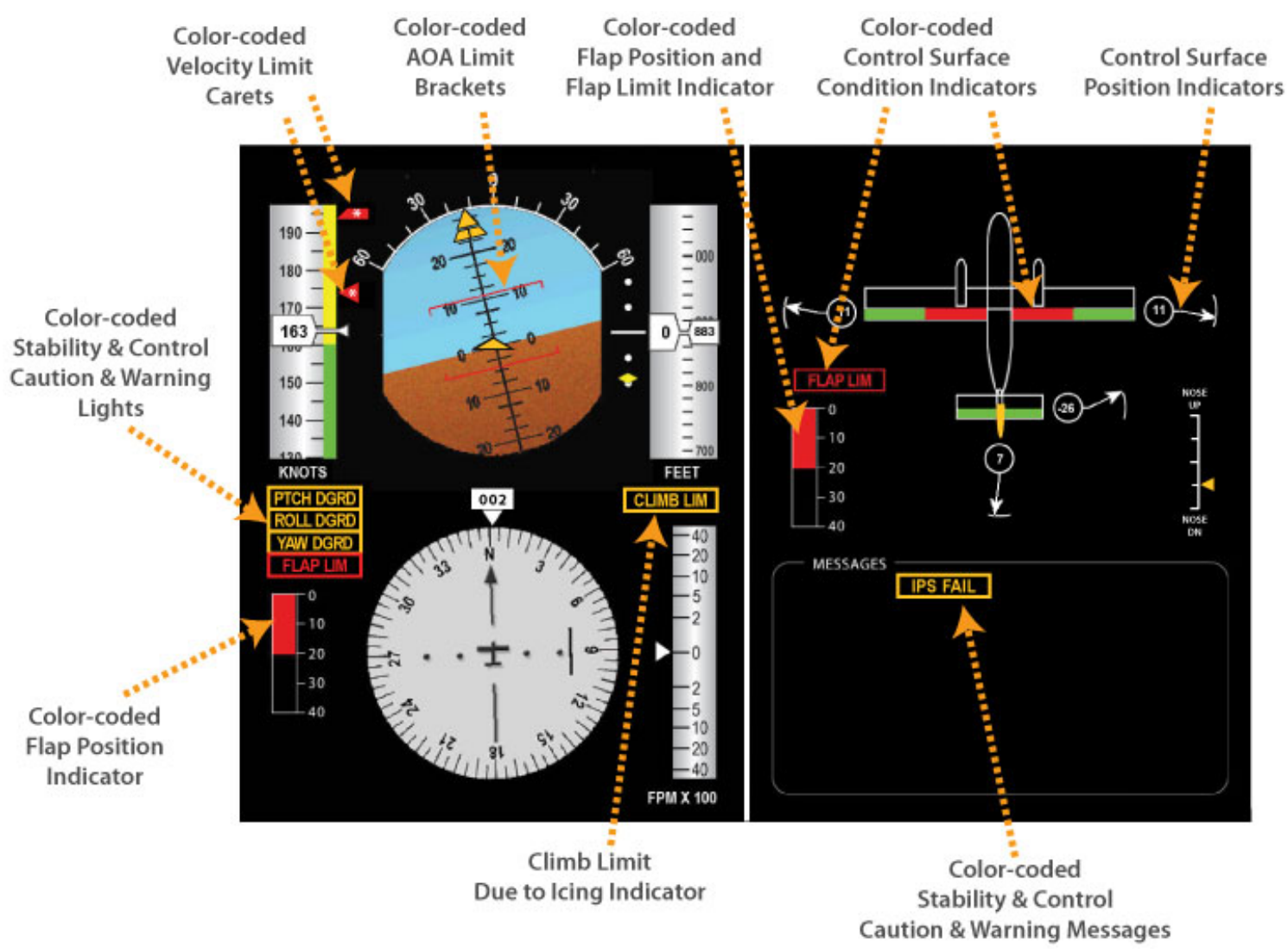

Figure 1.-ICEPro envelope protection cues on the primary flight display (left) and flight control status page (right).

When the system does not detect any change from the nominal a priori airplane characteristics, no cuing or messages appear and the instruments display the nominal flight information. When the system senses icing contamination that exceeds the system thresholds and latching logic, cues and possibly messages appear in conjunction with the normal display information.

There are three types of information that are provided when an icing contamination is determined:

- Airspeed limit carets and angle of attack limit brackets.

- These are displayed whenever an ice contamination is determined by the ICEPro system.

- Status messages

- These will appear, both on the primary flight display and on the Flight Control Display (FCD) page in the message box. They indicate that there is a control and/or stability degradation in the indicated axis. There is also a message that appears whenever the singleengine climb capability is outside of safe limits. A flap limit message will also appear when the flaps should be retracted back to a safer deflection.

- Flight control status indicators

- The FCD page includes a rough diagram of the airplane showing its control surfaces. The surfaces are colored and the color will change whenever degradation is determined in their axis. With no degradation, the surfaces are green and turn amber when there is a caution displayed for that axis and red when there is a warning.

The ICEPro System has three modes of operation: a MONITOR mode that provides initial detection of in-flight icing, an ID mode that provides a diagnosis of the condition, and a REPORTING mode, providing the prognosis of the condition and mitigation through cueing. Figure 2 presents a simplified flow diagram of the system modes and states. Details, such as latching and de-latching logic and specific logic for driving 
each of the caution/warning messages have been omitted to reduce the complexity of the diagram. Details of the system design can be found in a paper presented by D.R. Gingras at the 2009 Aerospace Sciences Conference in Orlando, Florida (Ref. 14). As indicated in the diagram the system is heavily dependent on input from two components: The Dynamic Inversion Control Evaluation System (D-ICES), an algorithm that provides predictions of clean and iced aircraft flight characteristics, and a real-time parameter identification routine. Results from these components are used to determine an Icing Severity Parameter (ISP) which is used in logic for issuing pilot cues and warnings during the reporting mode.

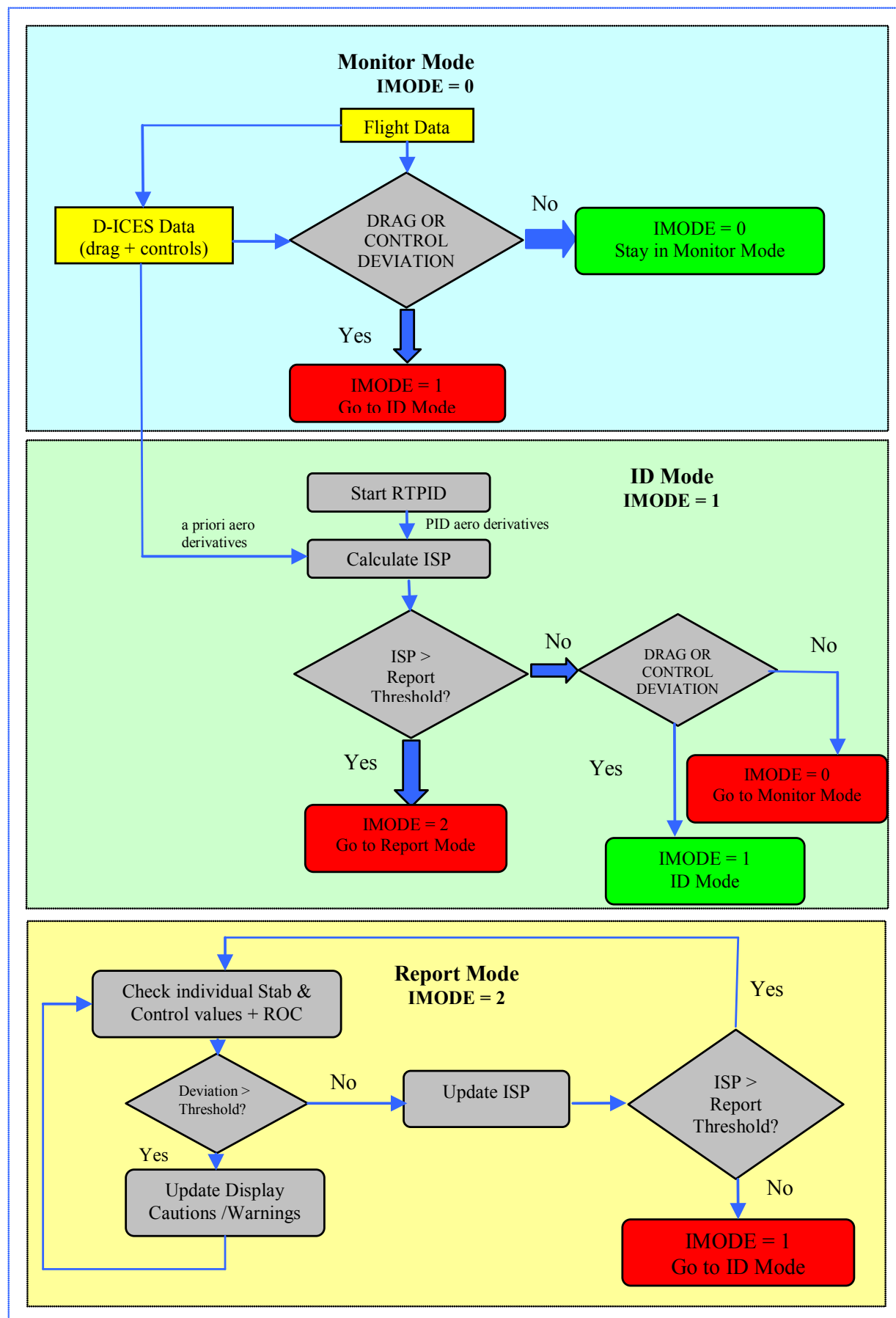

Figure 2.-Simplified ICEPro system state diagram. 


\section{Flight Characteristic Predictions}

\section{Development}

The flight characteristics predictions of the vehicle are made using a system hosted flight model, which for the development was that of a DeHavilland DHC-6 Twin Otter. This flight model was derived from a comprehensive nonlinear 6-degree-of-freedom simulation that was developed by Bihrle Applied Research and engineers at the NASA Glenn Research Center (Ref. 15). This model was based on data from extensive wind-tunnel tests using sub-scale models of the Twin-Otter and supplemented with flight data provided by NASA. This model covers the entire flight envelope including stall and post-stall flight regimes with and without icing effects resulting from ice accretion on the main wing, horizontal tail, and vertical tail.

During previous efforts this model had undergone extensive validation against flight data to achieve high confidence predictions of aerodynamic characteristics in clean, no ice configuration, as well as the aerodynamic characteristics from an iced configuration representing an IPS failure situation. Figure 3 contains a flow diagram of the process used during this effort to ensure accurate predictions of the aerodynamic coefficients. Figure 4 contains an example of the resulting comparisons with flight data of an elevator doublet for the clean airplane.

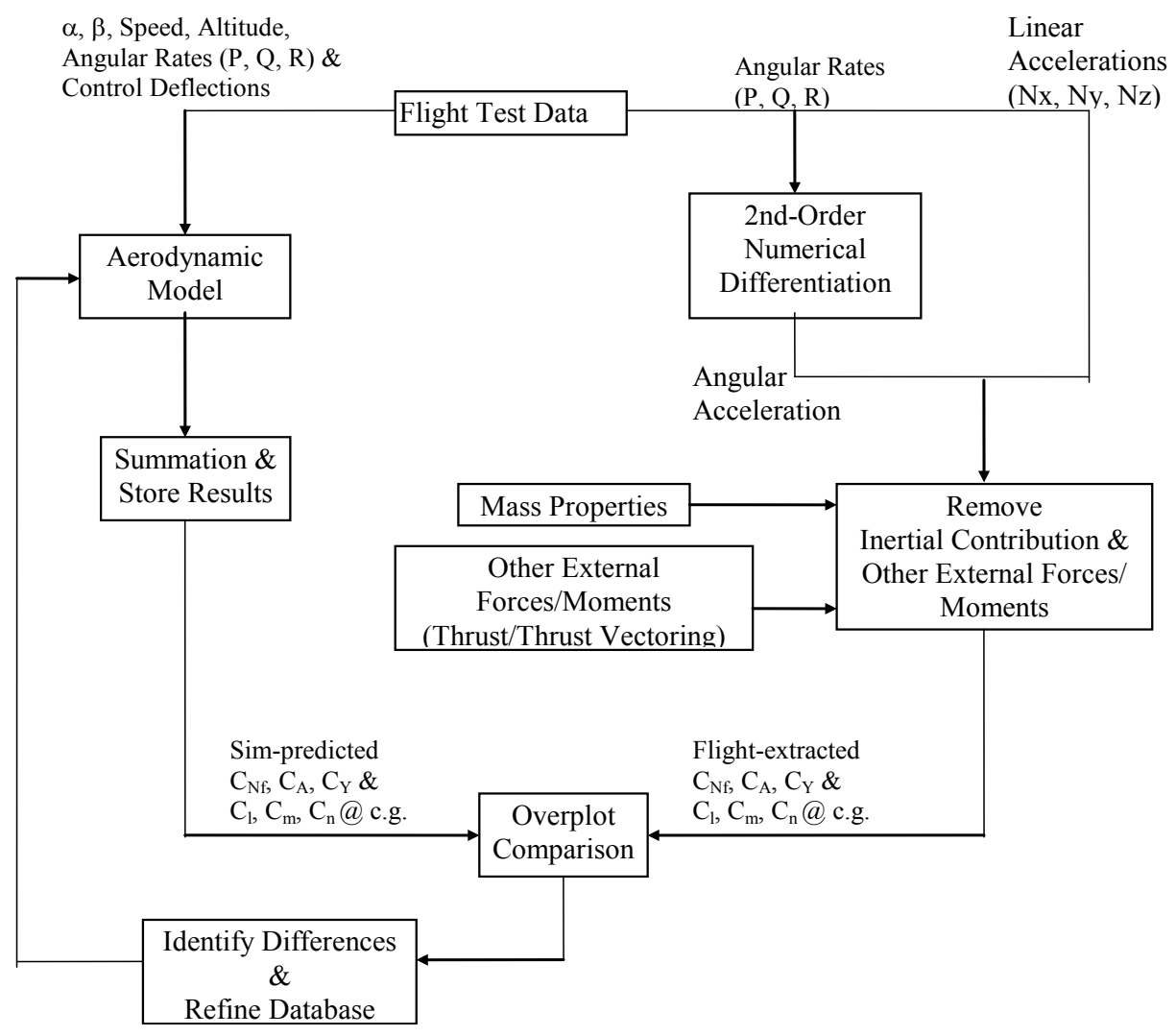

Figure 3.-Process used for aerodynamic model validation. 

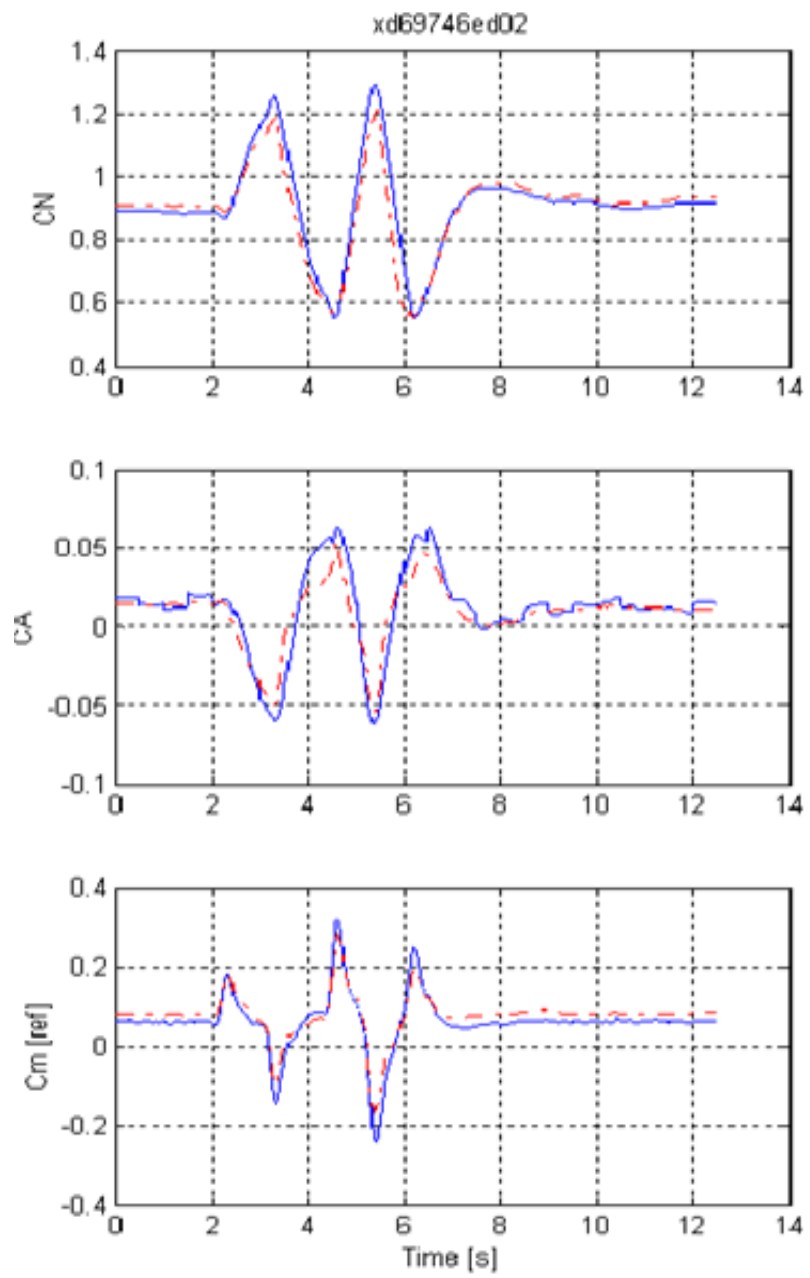

Figure 4.-Example of comparisons of the simulation model and flight aerodynamic coefficients.

In the ICEPro system this model is driven using a process similar to that show in Figure 3. Instead of recorded flight data as the input, predictions of clean and ice contaminated aerodynamic characteristics are determined using real-time flight measured state and control surface data.

\section{Real-Time Model Estimates}

Because the system compares model predictions described above with the current state, real time estimates are used. These estimates are computed by invoking real-time parameter identification (RTPID). The RTPID algorithm being employed was developed by Morelli (Ref. 16), and is based on a frequency domain approach implemented in version 2.0 of System IDentification Programs for AirCraft (SIDPAC) (Refs. 17 and 18).

The approach uses a linearized model of the vehicle dynamics, Equation (1), where $A, B, C$, and $D$ are matrices containing stability and control derivatives.

$$
\begin{aligned}
& \dot{x}(t)=A x(t)+B u(t) \quad x(0)=x_{o} \\
& y(t)=C x(t)+D u(t)
\end{aligned}
$$


Time-varying estimates of the stability and control derivatives are determined using measured airplane control surface deflections and measured states from air data, angular rates, and attitude. Outputs are rotational and translational accelerations. To determine the estimates, a cost function is formulated in the frequency domain from the Fourier transform of the model in Equation (1),

$$
\begin{aligned}
& j \omega \tilde{x}(\omega)=A \tilde{x}(\omega)+B \tilde{u}(\omega) \\
& \tilde{y}(\omega)=C \tilde{x}(\omega)+D \tilde{u}(\omega)
\end{aligned}
$$

The cost function is

$$
J_{k}=\frac{1}{2} \sum_{n=1}^{m}\left|j \omega_{n} \tilde{x}_{k}(n)-a_{k} \tilde{x}(n)-b_{k} \tilde{u}(n)\right|^{2} \quad \text { for } m \text { frequencies }
$$

where $a_{k}$ and $b_{k}$ are the $k$ th row of matrices $A$ and $B$, respectively, and $\tilde{x}_{k}(n) \equiv \tilde{x}_{k}\left(\omega_{n}\right), \tilde{u}_{k}(n) \equiv \tilde{u}_{k}\left(\omega_{n}\right)$. Each line in Equation (2) can be analyzed separately in this way, which implements an equation-error formulation (Ref. 16). The least squares cost function in each case can be formulated as

$$
J=\frac{1}{2}(Y-X \theta)^{\dagger}(Y-X \theta)
$$

where $^{\dagger}$ indicates complex conjugate transpose,

$$
Y=\left[\begin{array}{c}
j \omega_{1} \tilde{x}_{k}(1) \\
\vdots \\
j \omega_{m} \tilde{x}_{k}(m)
\end{array}\right] \quad X=\left[\begin{array}{cc}
\tilde{x}^{T}(1) & \tilde{u}^{T}(1) \\
\vdots & \vdots \\
\tilde{x}^{T}(m) & \tilde{u}^{T}(m)
\end{array}\right]
$$

and the unknown parameters from $A$ and $B$ are contained in the parameter vector $\theta$. The least squares parameter vector estimate is obtained as the value of $\theta$ that minimizes the cost function in Equation (4) (Ref. 19).

$$
\begin{aligned}
& \hat{\theta}=\left[\operatorname{Re}\left(X^{\dagger} X\right)\right]^{-1} \operatorname{Re}\left(X^{\dagger} Y\right) \\
& \operatorname{cov}(\hat{\theta}) \equiv E\left[(\hat{\theta}-\theta)(\hat{\theta}-\theta)^{T}\right]=\hat{\sigma}^{2}\left[\operatorname{Re}\left(X^{\dagger} X\right)\right]^{-1} \\
& \hat{\sigma}^{2}=\frac{1}{m}(Y-X \hat{\theta})^{\dagger}(Y-X \hat{\theta})
\end{aligned}
$$

Performing the identification in the frequency domain is advantageous for this application because of computational efficiency, robustness to noise and data dropouts, and reliable confidence bounds from the covariance matrix. To ensure reliable estimates, the ICEPro features a self checking algorithm that examines the confidence bound of the parameter estimates. Table 1 lists the parameters that are being identified in real-time.

If confidence of the estimated parameters falls below acceptable levels due to lack of data information content, an automated excitation of the aircraft control surfaces is triggered to improve data information content. This interface with the subject vehicle is performed as though an autopilot is driving control 
deflections using multi-frequency orthogonal inputs (Ref. 19). Amplitudes of the inputs are adjusted to provide excitation while minimizing vehicle motion.

\begin{tabular}{|} 
TABLE 1.-AERODYNAMIC PARAMETERS IDENTIFIED BY RTPID \\
\hline$C_{N_{\alpha}}$ & $C_{Y_{\delta a}}$ & $C_{l_{p}}$ \\
$C_{N_{\delta e}}$ & $C_{Y_{\delta r}}$ & $C_{l_{r}}$ \\
$C_{N_{q}}$ & $C_{Y_{p}}$ & $C_{n_{\beta}}$ \\
$C_{m_{\alpha}}$ & $C_{Y_{r}}$ & $C_{n_{\delta a}}$ \\
$C_{m_{\delta e}}$ & $C_{l_{\beta}}$ & $C_{n_{\delta r}}$ \\
$C_{m_{q}}$ & $C_{l_{\delta a}}$ & $C_{n_{p}}$ \\
$C_{Y_{\beta}}$ & $C_{l_{\delta r}}$ & $C_{n_{r}}$ \\
\hline
\end{tabular}

\section{System Implementation}

The ICEPro system was developed and deployed in Bihrle Applied Research's D-Six PC-based simulation environment. All of the ICEPro functions, including the software for driving the flight displays are provided in a single computer that runs the software in real time. The system can be interfaced with NASA's Ice Contamination Effects Flight Training Device, ICEFTD (Fig. 5), or mounted in the NASA Twin Otter aircraft for flight demonstrations. The system includes all of the Data Acquisition and Executive functions which control the various modules that make up the system.

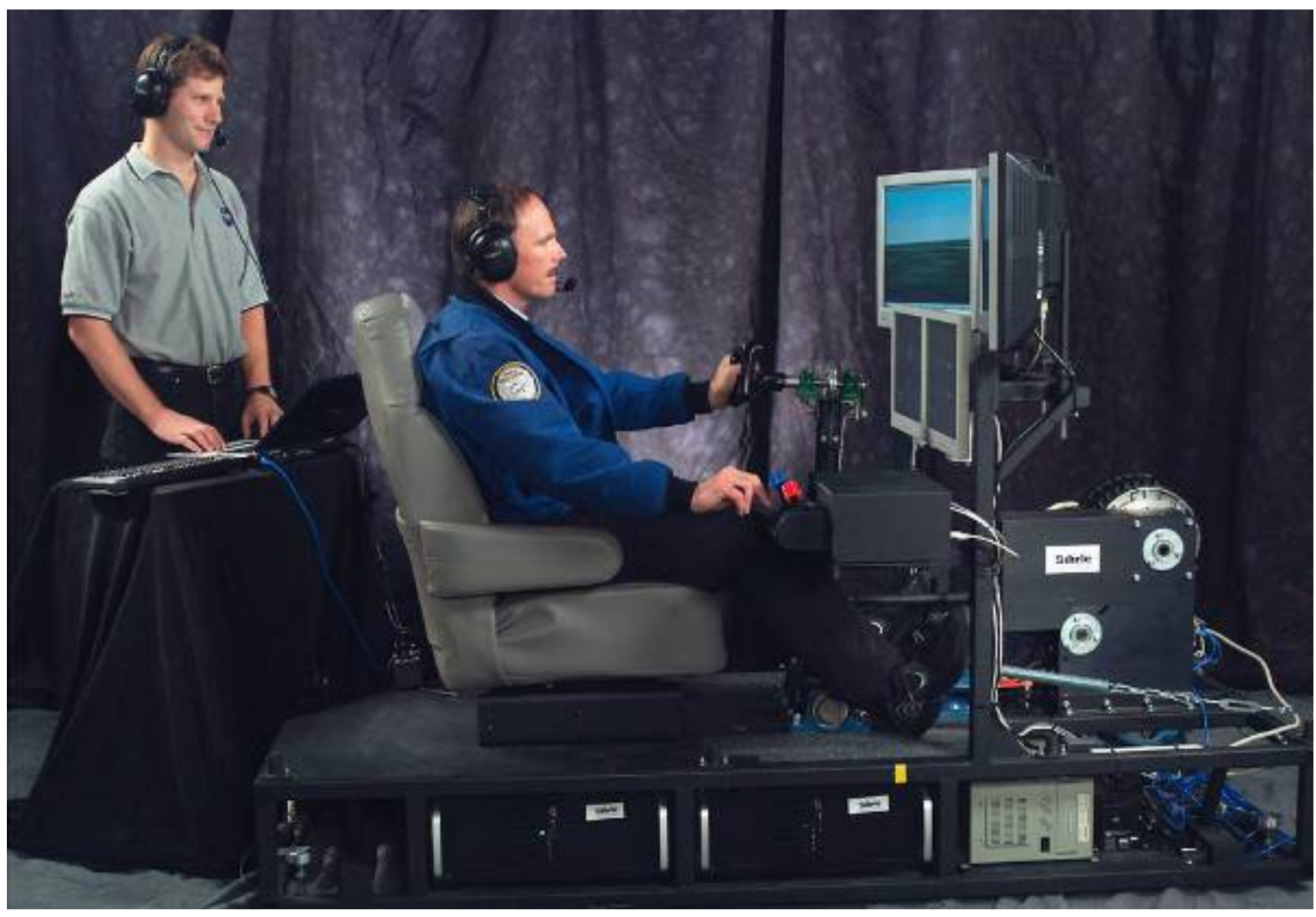

Figure 5.-NASA's Ice Contamination Effects Flight Training Device (ICEFTD). 
The data acquisition portion receives data from the data bus on the airplane or from an emulation of the airplane data system if it is working with the simulator and not the airplane. It then makes the appropriate data available to the various other modules for processing and to the cockpit displays. The Executive portion provides all of the logic and calculation modules required to determine the icing state and what cues should be provided to the pilot.

The ICEPro system was first developed using a desktop simulation running in D-Six. The module development and all of the initial check out and tuning were all done in this manner. Once the system was mature enough to permit piloted evaluations it was migrated to the ICEFTD, which also used the D-Six environment. On the desktop implementation, the ICEPro modules and the Twin Otter simulation were run on the same computer. For the ICEFTD implementation, a separate computer was used for the ICEPro modules. Communication with the ICEFTD was accomplished over an Ethernet connection. This implementation was used to closely emulate the hoped for eventual implementation in the actual airplane. If this were to occur, the same computer could be similarly connected to the airplane's data acquisition system. Because both the desktop simulation and the ICEPro computer attached to the ICEFTD were running in the D-Six environment, migration from one to the other entailed simply copying the module files from one to the other.

The ICEFTD piloted simulations provided synthetic environment to assess and tune the final thresholds and latching logic for the cues and messages. They also afforded the opportunity to assess the effect of control surface excitation for the RTPID routine on the pilot. The piloted simulation was also instrumental in evaluating the appearance and validity of the caution/warning messages, and for development and evaluation of aural and tactile cues that were incorporated for the guest pilot evaluations that were subsequently performed following the development stage. They were also used to develop and evaluate the scenario to be used for the guest pilot evaluations.

\section{Engineering Station}

An engineering station was set up that enabled the operator to set key parameters of the ICEPro system, monitor the performance of the system, and interact with the implemented logic during the development and evaluation phases of the program. The engineering station consisted of a set of Graphical User Interfaces (GUIs) that were displayed on two monitors attached to the computer running the ICEPro routines.

The first window (Fig. 6) shows the status of the system. It shows in which mode the system is currently operating (Monitor, ID, or Report), whether the controls are being excited, the duration and magnitude of the excitations in each axis, as well as the time since reset of both the D-ICES and Real Time Parameter Identification (RT-PID) modules. There is also a window that displays system status messages and buttons to reset the system modules and settings.

The duration and magnitude of the surface excitations can be adjusted in this GUI and the excitation can be manually triggered when the system is in the ID or Report modes. It is also possible to manually reset either the D-ICES or RT-PID routines from this window.

There are a series of default thresholds, time delays, etc. that are used by the ICEPro logic modules that are preloaded with the system. All of the default values of these parameters can be overridden by inputting new values in an included text file. There are two buttons at the bottom of the GUI to either update these system settings from the text file, or to reset them to the default values.

The D-ICES status window (Fig. 7) shows the a priori model values of the longitudinal and lateraldirectional derivates for both the clean and fully iced airplanes at the current aircraft states. These linearized derivatives are extracted at the current state from the stored non-linear model data contained in the D-ICES routines. The set of derivatives presented are the same ones that are extracted by the RT-PID module.

There is also a similar window for the RT-PID system that shows the comparable real time PID determined derivatives (Fig. 8). Because the RT-PID system only runs in the ID and Report modes, the values will not be updated when the system is operating in the Monitor mode. The operator can readily 
compare the values from the D-ICES and RT-PID status windows to evaluate the differences between the a priori clean or iced values, and the current actual values as determined by RT-PID. A set of plots of such a comparison is presented in Figure 9.

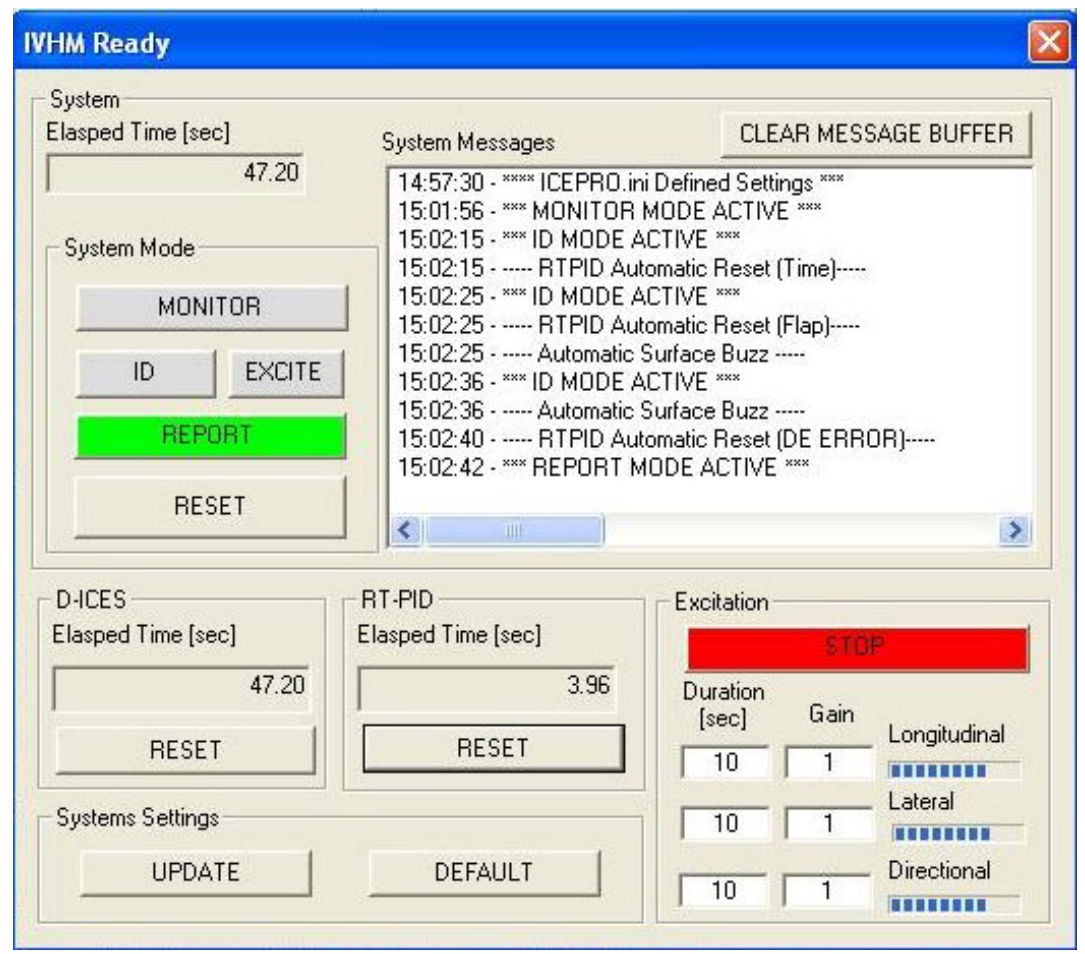

Figure 6.-System status window.

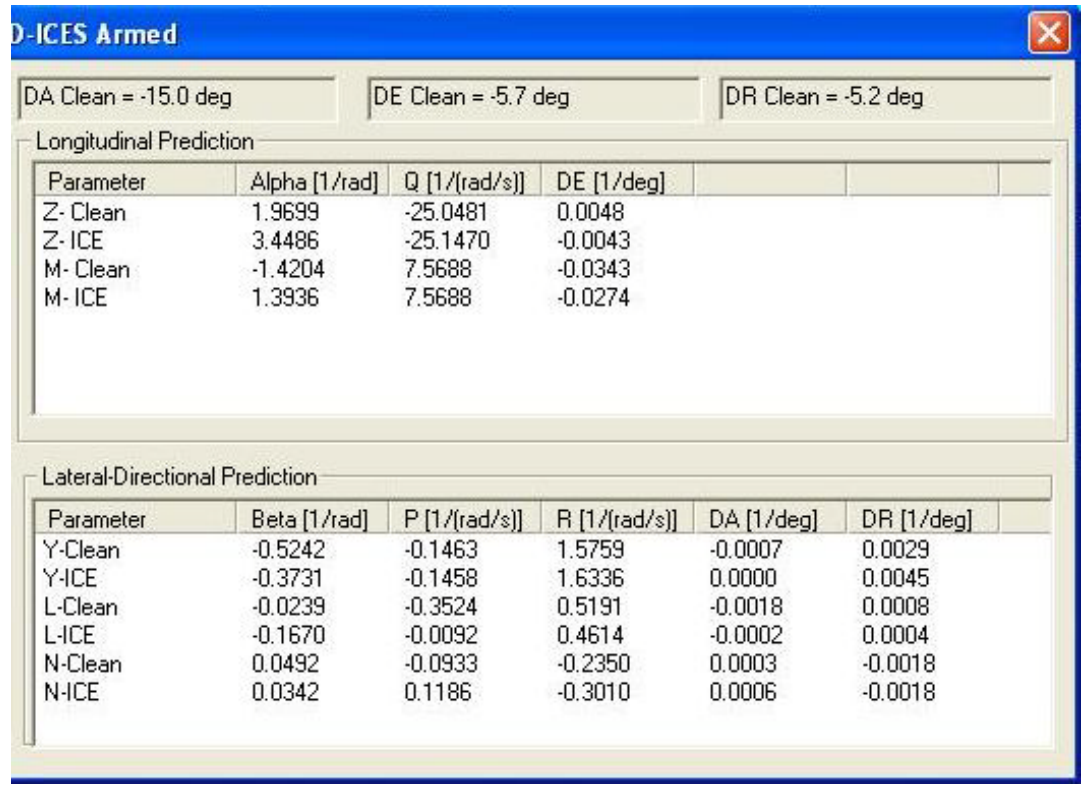

Figure 7.-D-ICES status window. 


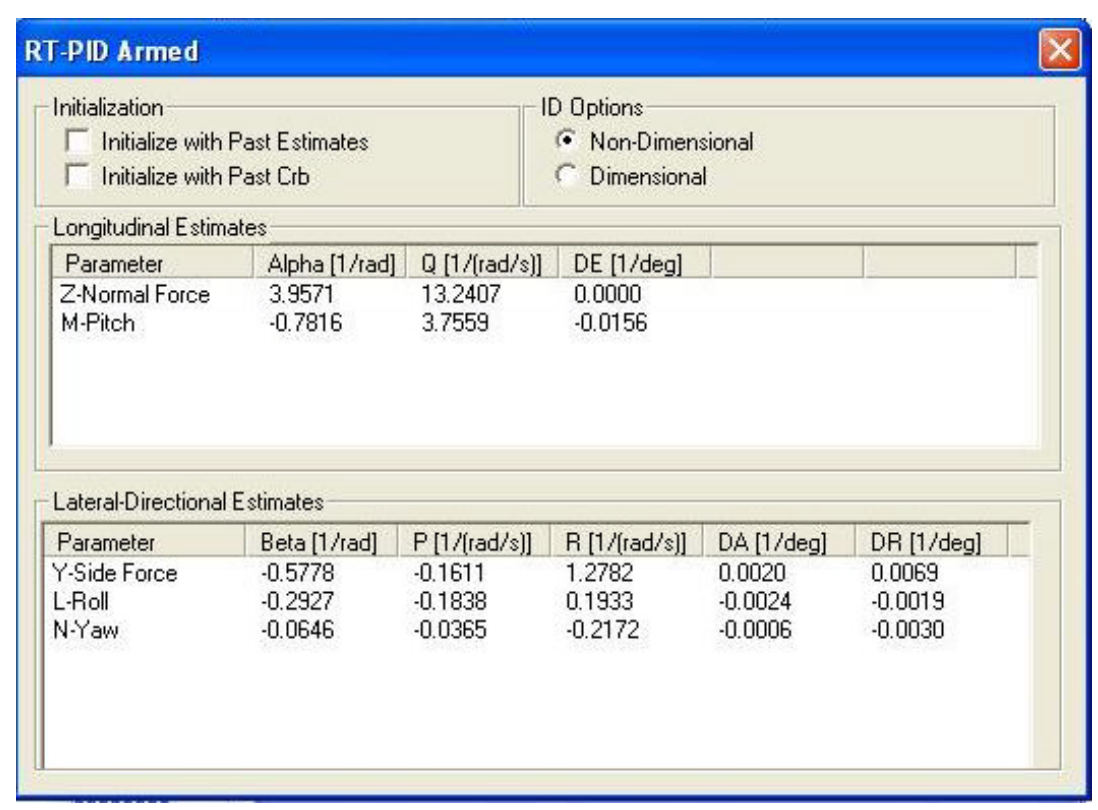

Figure 8.-RT-PID status window.
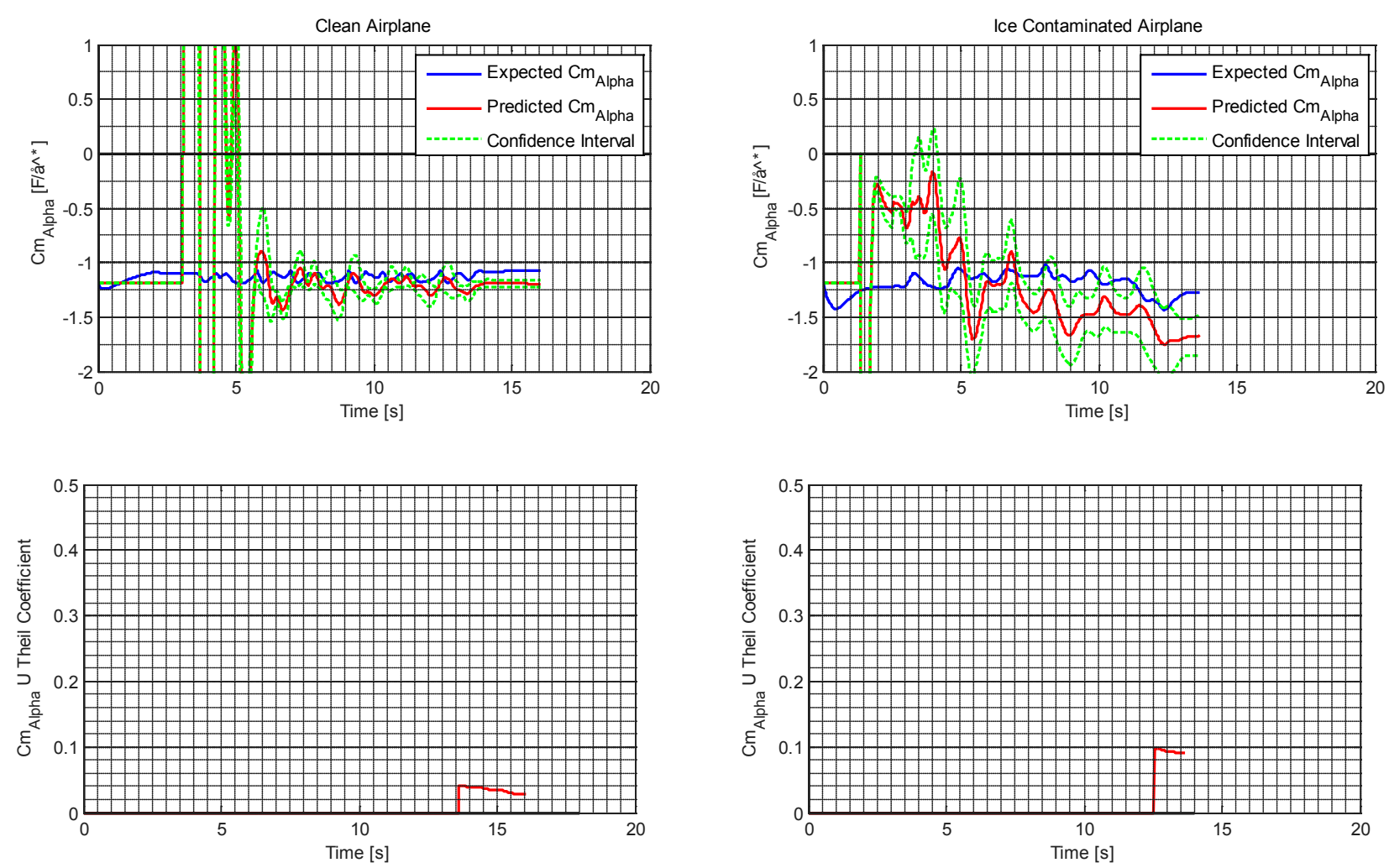

Figure 9.-Comparison of RT-PID results with D-ICES predictions, with and without contamination.

Because the ICEPro system modules are running within a D-Six project, all of the normal D-Six interface tools are also available at the engineering station. As a result, any of the aircraft variables that are passed from the ICEFTD as the simulated airplane data bus are available to monitor in real time listings, on strip charts, or as post-run engineering plots. Pertinent ICEPro variables are placed in data matrices that are also passed as D-Six variables and are similarly available for real time monitoring and 
post-run analysis. At the end of the run, the time histories of these variables can be recorded for later analysis or for play back. The system also provides for strip charts of any of the RT-PID derivative values along with their expected values and the calculated error bands of the data.

For the piloted evaluations, the ICEFTD was enclosed within a black curtain that was provided to isolate the evaluation pilots form the rest of the room, thus providing a more realistic environment with no outside distractions. Consequently, the person manning the engineering station could not see the ICEFTD instrument panel. Therefore, a copy of the PFD that duplicated the information displayed to the pilot was provided for monitoring at the engineering station.

\section{System Calibration}

A considerable amount of effort was expended fine-tuning the system to develop a tool that would provide adequate warning and guidance when an icing condition was encountered but which would not have any false indications or nuisance messaging. The efforts to accomplish this evolved into three main areas: determining which terms to include in the ISP calculation, tuning thresholds and latching and delatching logic, and developing logic for when the RT-PID routine gets reset.

\section{Icing Severity Parameter Determination}

As shown in Equation (7), the ISP was formulated as the sum of the difference between the actual (RT-PID derived values) and expected (a priori clean) derivative values divided by the difference between the a priori clean and fully iced values for the selected derivatives. It was found to be impractical to use all of the RT-PID derived terms. The yawing moment terms did not change appreciably for the icing condition for this airplane, and did not prove useful to include. The damping terms, such as $C_{m_{q}}$ and $C_{l_{p}}$, which did show differences with icing, were the most difficult for RT-PID to obtain with great accuracy, and proved to adversely affect the robustness of the ISP calculation and so were not used.

$$
I S P=\frac{\sum_{i=1}^{n}\left[\frac{\left(\text { Value }_{\text {expected }}-\text { Value }_{\text {actual }}\right)_{i}}{\left(\text { Value }_{\text {expected }}-\text { Value }_{\text {iced }}\right)_{i}}\right]}{n}
$$

The control terms, i.e., the $\delta_{\mathrm{e}}$ and $\delta_{a}$ moment derivatives, were generally determined with great accuracy by the RT-PID routine, and showed icing effects very well. Consequently, they were used for the calculation. Elevator deflection did not strongly affect the normal force coefficient, and therefore this term was not used. The terms for longitudinal and lateral stability, $C_{m_{\alpha}}$ and $C_{l_{\beta}}$ were also used. The final terms that ended up being used, were:

\begin{tabular}{|c|c|}
\hline$C_{m_{\alpha}}$ & $C_{l_{\beta}}$ \\
$C_{m_{\delta e}}$ & $C_{l_{\delta \alpha}}$ \\
$C_{N_{\alpha}}$ & \\
\hline
\end{tabular}

Additional logic was also added to consider the relative predicted error in each term, in the form of

$$
\left|\frac{R T-P I D_{-} \text {error }}{R T-P I D_{\text {_value }}}\right|
$$

If the relative error for any term became larger than an experimentally determined threshold, the term was dropped from the ISP calculation. As a result, any term whose error represented a sufficiently large portion of its total value would not adversely influence the ISP calculation. As will be discussed further, 
the relative error in the pitching moment due to elevator deflection derivative was such a critical value to the ISP calculation and one of the earliest indicators of building errors in the RT-PID results, that its relative error build up was used as one of the keys to forcing a reset of the RT-PID routine.

\section{Thresholds and Latching}

For each change in mode of operation as well as messaging, there were thresholds that needed to be met before the change could occur or the message appear. There was also latching and delatching logic that specified that the condition had to be met for a specified period of time before it would appear and, conversely, the condition had to disappear for a period of time for it to be removed. These were incorporated so that the messages would not "flash" off and on if the conditions were right on the edge of meeting the requirements for display.

\section{RT-PID Reset}

As was mentioned earlier, it was found that it was necessary to force a reset of the RT-PID routine periodically for best operation. The RT-PID calculations make use of past values which works well if there is no change in the aircraft configuration or flight condition. However, when there are changes, the time histories of past values can incorrectly influence the calculations at the new configuration and/or flight condition. Consequently, a reset, which flushes the buffers and essentially restarts the calculations, is required whenever those conditions occur. In addition, evaluations of the system showed that better results would occur with periodic resets even when no significant changes occurred. For the evaluation phase, the system was set to do an RT-PID reset after $50 \mathrm{sec}$ if one did not occur before then for either of the other two specified reasons. While control excitations were not directly commanded upon reset, they generally did occur shortly after the reset because the reset created the conditions that caused the system to command the excitations.

\section{Conditions for Warning/Caution Messages}

Messages that warned of deficiencies in a particular axis or of aircraft performance limitations were displayed on the PFD. The conditions under which these messages would appear, and whether they appeared as cautions (amber messages) or warnings (red messages) were based on the amount of degradation in certain aerodynamic parameters from the baseline clean airplane values. Whenever a caution or warning message is displayed, the corresponding primary control surface on the airplane representation on the FCD page is also colored appropriate to the message (amber for cautions and red for warnings). The caution or warning message is also repeated in the message section of the FCD page.

The initial trials of the ICEPro system considered stability and damping terms in each axis, as well as control effectiveness to determine when a caution or warning message should be displayed. In practice, it was found that the meaningful stability and damping thresholds were rarely attained and so these terms were dropped and only the control effectiveness terms were used. Consequently, the conditions that will generate a pitch, roll, or yaw degraded message are as shown below (because the control derivatives are all negative terms, the inequality signs may seem reversed):

$$
\begin{aligned}
& 0.50 \cdot C_{m \delta e_{-} n o \cdot i c e} \leq C_{m \delta e}<0.25 \cdot C_{m \delta e_{-} n o \cdot i c e}, \text { then amber PTCH DGRD and amber } \delta e \text { on FCD } \\
& C_{m \delta e} \leq 0.25 \cdot C_{m \delta e_{-} n o \cdot i c e}, \text { then red PTCH DGRD and red } \delta e \text { on FCD } \\
& 0.50 \cdot C_{n \delta r_{-} n o \cdot i c e} \leq C_{n \delta r}<0.25 \cdot C_{n \delta r_{-} n o \cdot i c e} \text {, then amber YAW DGRD and amber } \delta r \text { on FCD } \\
& C_{n \delta r} \leq 0.25 \cdot C_{n \delta r_{-} n o \cdot i c e}, \text { then red YAW DGRD and red } \delta r \text { on FCD } \\
& 0.50 \cdot C_{l \delta a \_n o \cdot i c e} \leq C_{l \delta a}<0.25 \cdot C_{l \delta a \_n o \cdot i c e}, \text { then amber ROLL DGRD and amber } \delta a \text { on FCD } \\
& C_{l \delta a} \leq 0.25 \cdot C_{l \delta a \_n o \cdot i c e}, \text { then red ROLL DGRD and red } \delta a \text { on FCD }
\end{aligned}
$$


Calculations of single engine rate of climb capability were made using the simulation data and Twin Otter handbook values. Tables of these values as functions of flap deflection, ice condition, and altitude were stored in the ICEPro routines. Whenever the system was in the Reporting mode and the flight and icing condition resulted in predicted single engine rate of climb levels below specified thresholds, a climb limit caution or warning message would appear on the PFD and in the FCD message box. In addition, a corresponding flap limit message would appear and the flaps on the airplane representation presented on the FCD page would be colored either amber or red, corresponding to the caution/warning messages. This was meant to alert the pilot that the flap deflection should be reduced for safe operation in the event of an engine failure. The thresholds used during the evaluations were:

$0 \mathrm{fpm}<$ SingEngROC $\leq 100 \mathrm{fpm}$, then amber CLMB LIM and FLAP LIM

SingEngROC $\leq 0 \mathrm{fpm}$, then red CLMB LIM and FLAP LIM

\section{Stall Warning and Decluttering}

A stall warning was added to the system that consisted of a large red STALL message appearing near the middle of the PFD and an aural two-note tone. The aural warning would come on whenever the calculated stall angle of attack was attained, and the message would appear on the PFD when the angle of attack was $2^{\circ}$ above the calculated stall angle. During the system development, it was found that during the low-speed highly dynamic environment present during a stall, RT-PID data extraction evidently had trouble keeping up with the rapid change in aerodynamic characteristics in that region and some extraneous warning/caution messages would appear, and then would go away after the airplane was stabilized. Rather than spend a significant time refining the thresholds and logic, it was decided, based on piloted evaluations during the development, that it was best to eliminate the messaging entirely during a stall and recovery to allow the pilot to concentrate on recovering the airplane without the distractions of any messages. Consequently, logic was incorporated to "declutter" the PFD by eliminating all ICEPro related messaging during this period. The angle of attack bars and speed carets did remain on the PFD, because these would aid the pilot during the recovery effort. While these cues do depend somewhat on the RT-PID results as it affects the ISP, the ISP calculation is heavily filtered to yield a more or less steadystate level and should be only marginally influenced by the rapid changes during a stall and recovery.

\section{Accommodations for Pilot Evaluations}

In preparation for the piloted evaluations that took place during August 2009, several additions were added to the simulation. To represent to the pilot that he was operating an aircraft without icing protection, a message stating "IPS failure" was displayed in the FCD message box along with an aural cue to indicate that the icing protection system had failed.

A stick shaker and stick pusher function were added to the longitudinal yoke loader. These were configured to operate in a manner consistent with real-world shakers and pushers and would act as a forceful cue to the pilot that wing stall was about to, or had occurred. The shaker was sufficiently rapid and forceful that it could not be missed during the most intense flight condition. The pusher was forceful enough that it would force the airplane back to an un-stalled angle of attack. Monitoring when the shaker or pusher was activated also proved to be an important tool in interpreting and assessing the performance during post-flight analysis.

The shaker was configured to come on at the same time as the angle of attack bars turned from white to amber, which was $2^{\circ}$ below the stall angle of attack. The stick pusher came on at approximately the same time that the stall message appeared on the PFD.

\section{Conclusion}

In keeping with the NASA goal to improve the safety of commercial and general aviation aircraft, an envelope protection system was developed using no direct ice detection devices. Through the use of 
measured data, a priori information, and real-time stability and control estimates, this system computes an icing severity parameter. This parameter is used to trigger appropriate pilot cueing to warn the pilot of hazardous conditions and provide guidance for action to mitigate the situation. The main advantage of the system is that it uses data that are readily available in modern avionics systems and once adjusted to specific aircraft makes and models, and mated to modern display systems, should provide sufficient pilot cueing for envelope protection against icing related incidents.

The utility of the Icing Contamination Envelope Protection (ICEPro) system for mitigating a potentially hazardous icing condition was evaluated by 29 pilots using the ICEFTD. The pilots participating in this test were divided into two groups; a control group using baseline displays without ICEPro, and an experimental group using ICEPro driven display cueing. Each group flew identical precision approach and missed approach procedures with a simulated ice protection failure icing configuration. Pilot performance, workload, and survey questionnaires were collected for both groups of pilots. Results showed that real time assessment cues were effective in reducing the number of potentially hazardous upset events and in lessening exposure to loss of control following an incipient upset condition. Pilot workload with the added ICEPro displays was not measurably affected, but pilot opinion surveys showed that real time cueing greatly improved their situation awareness of a hazardous aircraft state. A detailed discussion of these evaluations and results are presented in another paper presented at this conference (Ref. 19). 



\section{Appendix.-Symbols List}

\begin{tabular}{|c|c|}
\hline$A$ & Stability matrix \\
\hline$a_{k}$ & $k$-th row of matrix A \\
\hline$B$ & Control matrix \\
\hline$b_{k}$ & $k$-th row of matrix B \\
\hline$C$ & Stability matrix \\
\hline$b$ & Reference span \\
\hline $\bar{c}$ & Mean aerodynamic chord \\
\hline$C_{l_{\beta}}$ & Rolling moment due to sideslip angle derivative, $\partial C_{l} / \partial \beta$ \\
\hline$C_{l_{\delta a}}$ & Rolling moment due to aileron deflection derivative, $\partial C_{l} / \partial \delta_{a}$ \\
\hline$C_{l_{\delta r}}$ & Rolling moment due to rudder deflection derivative, $\partial C_{l} / \partial \delta_{r}$ \\
\hline$C_{l_{p}}$ & Rolling moment due to non-dimensional roll rate derivative, $\partial C_{l} / \partial(p b / 2 \mathrm{~V})$ \\
\hline $\mathrm{C}_{l_{r}}$ & Rolling moment due to non-dimensional yaw rate derivative, $\partial C_{l} / \partial(r b / 2 \mathrm{~V})$ \\
\hline$C_{m_{\alpha}}$ & Pitching moment due to angle of attack derivative, $\partial C_{m} / \partial \alpha$ \\
\hline$C_{m_{\delta e}}$ & Pitching moment due to elevator deflection derivative, $\partial C_{m} / \partial \delta_{e}$ \\
\hline$C_{m_{q}}$ & Pitching moment due to non-dimensional pitch rate derivative, $\partial C_{m} / \partial(q \bar{c} / 2 V)$ \\
\hline$C_{N_{\alpha}}$ & Normal force due to angle of attack derivative, $\partial C_{N} / \partial \alpha$ \\
\hline$C_{N_{\delta e}}$ & Normal force due to elevator deflection derivative, $\partial C_{N} / \partial \delta_{e}$ \\
\hline$C_{N_{q}}$ & Normal force due to non-dimensional pitch rate derivative, $\partial C_{N} / \partial(q \bar{c} / 2 \mathrm{~V})$ \\
\hline$C_{n_{\beta}}$ & Yawing moment due to sideslip angle derivative, $\partial C_{n} / \partial \beta$ \\
\hline$C_{n_{\delta a}}$ & Yawing moment due to aileron deflection derivative, $\partial C_{n} / \partial \delta_{a}$ \\
\hline$C_{n_{\delta r}}$ & Yawing moment due to rudder deflection derivative, $\partial C_{n} / \partial \delta_{r}$ \\
\hline$C_{n_{p}}$ & Yawing moment due to non-dimensional roll rate derivative, $\partial C_{n} / \partial(p b / 2 V)$ \\
\hline$C_{n_{r}}$ & Yawing moment due to non-dimensional yaw rate derivative, $\partial C_{n} / \partial(r b / 2 V)$ \\
\hline$C_{Y_{\beta}}$ & Side force due to sideslip angle derivative, $\partial C_{Y} / \partial \beta$ \\
\hline$C_{Y_{\delta a}}$ & Side force due to aileron deflection derivative, $\partial C_{Y} / \partial \delta_{a}$ \\
\hline$C_{Y_{\delta} r}$ & Side force due to rudder deflection derivative, $\partial C_{Y} / \partial \delta r$ \\
\hline$C_{Y_{p}}$ & Side force due to non-dimensional roll rate derivative, $\partial C_{Y} / \partial(p b / 2 V)$ \\
\hline$C_{Y_{r}}$ & Side force due to non-dimensional yaw rate derivative, $\partial C_{Y} / \partial(r b / 2 \mathrm{~V})$ \\
\hline$D$ & Control matrix \\
\hline$F C D$ & Flight Control Display \\
\hline$I P S$ & Ice Protection System \\
\hline
\end{tabular}




\begin{tabular}{ll}
$I S P$ & Icing Severity Parameter \\
$J$ & Cost function \\
$L S E$ & Least-squared error \\
$P F D$ & Primary Flight Display \\
$R M S$ & Root-mean square \\
$S L D$ & Super-cooled Large Droplet \\
$t$ & Time \\
$U$ & Theil Coefficient \\
$u$ & Control vector \\
$\hat{u}$ & Control vector predicted from inversion routine \\
$\tilde{u}_{k}$ & Control \\
$V$ & True velocity, ft/s \\
$y, \quad \hat{y}$ & Measured and predicted output \\
$x$ & State vector \\
$x_{0}$ & State vector initial condition \\
$\tilde{x}_{k}$ & State \\
$\theta$ & Parameter vector \\
$\hat{\theta}$ & Estimated parameter \\
$\hat{\sigma}$ & Confidence bound \\
$\omega$ & Frequency, rad/s \\
\hline &
\end{tabular}




\section{References}

1. National Transportation Safety Board, Factual Report on Cessna CE-208 Caravan Accident on Oct. 21, 2001 at Dillingham, AK, NTSB ID DCA02MA003.

2. National Transportation Safety Board, Crash During Approach to Landing, Circuit City Stores, Inc., Cessna Citation 560, N500AT, Pueblo, CO, Feb. 16, 2005, Aircraft Accident Report NTSB/AAR07/02. Washington, D.C., Jan. 2007.

3. National Transportation Safety Board, In-Flight Icing Encounter and Loss of Control, Simmons Airlines, D.B.A. American Eagle Flight 4184 Avions De Transport Regional (ATR) Model 72-212, N401am, Roselawn, IN, Oct. 31,1994, NTSB Aircraft Accident Report, NTSB/AAR-96/01, Washington, D.C., Jul. 1996.

4. National Transportation Safety Board, In-Flight Icing Encounter And Uncontrolled Collision With Terrain; Comair Flight 3272; Embraer Emb-120rt, N265ca; Monroe, MI, Jan. 9, 1997, NTSB Aircraft Accident Report, NTSB/AAR-98/04, Washington D.C., Nov. 1998.

5. Transportation Safety Board of Canada, Loss of Control on Go-around (Rejected Landing), Air Canada Canadair CL-600-2B19 C-FSKI, Fredericton Airport, New Brunswick, Report Number A97H0011, Dec. 1997.

6. Aviation Safety Council, GE791 Occurrence Investigation Report, In-Flight Icing Encounter and Crash into the Sea Transasia Airways Flight 791, ATR72-200, B-22708, 17 Kilometers Southwest of Makung City, Penghu Islands, Taiwan, Dec. 21, 2002, ASC-AOR-05-04-001, Taipei, Taiwan.

7. Inflight Loss of Control due to Airframe Icing Saab 340B, VH-OLM, 28 Jun. 2002, Australian Transport Safety Bureau Air Safety Investigation BO/2002030704, Dec. 2003.

8. "Roll Oscillations on Landing, Air Canada, Airbus 321-211, C-GJVX and C-CIUF, Toronto/Lester B. Pearson International Airport, Ontario, 07 December 2002," Transportation Safety Board of Canada Aviation Investigation Report A02O0406.

9. Jones, S.M., Reveley, M.S., Evans, J.K., and Barrientos, F.A., "Subsonic Aircraft Safety Icing Study," NASA/TM-2008-215107, Jan. 2008.

10. National Transportation Safety Board, Safety Recommendation to Mitigate the Existing Risk to the Cessna 208 Fleet During the Current Icing Season. A-06-01 through -03, Jan. 17, 2006.

11. National Transportation Safety Board, Safety Recommendation to Mitigate the Existing Risk to the Saab 340 Fleet When Operating in Icing Conditions. A-06-48/51, Jul. 10, 2006.

12. Russell, P., and Pardee, J., "Joint Safety Analysis Team-CAST Approved Final Report Loss of Control JSAT Results and Analysis," Dec. 2000.

13. Bragg, M.B., Basar, T., Perkins, W.R., Selig, M.S., Voulgaris, P.G., Melody, J.W., Sarter, N.B., Smart Icing Systems for Aircraft Icing Safety, AIAA-2002-0813, Jan. 2002.

14. Gingras, D.R, Barnhart, B., Ranaudo, R., Ratvasky, T., and Morelli E., "Envelope Protection for InFlight Ice Contamination,” NASA/TM-2010-216072, AIAA-2009-1458, Jan. 2009.

15. Barnhart B.P, Dickes, E, Gingras D.R., and Ratvasky, T.P., "Simulation Model Development for Icing Effects Flight Training," NASA/TM-2003-212115, SAE 2002-01-1527, Apr. 2003.

16. Morelli, E.A., "Real-Time Parameter Estimation in the Frequency Domain," Journal of Guidance, Control, and Dynamics, Vol. 23, No. 5, Sep.-Oct. 2000, pp. 812-818.

17. Morelli, E.A., "System IDentification Programs for AirCraft (SIDPAC)," AIAA-2002-4704.

18. Klein, V and Morelli, E.A., Aircraft System Identification Theory and Practice, American Institute for Aeronautics and Astronautics Inc., Reston, VA, 2006.

19. Ranaudo, R., Martos, B., Norton, B., Gingras, D., Barnhart, B., Ratvasky, T., and Morelli, E., "Piloted Simulation to Evaluate the Utility of a Real Time Envelope System for Mitigating In-Flight Icing Hazards,” AIAA-2010-7987, Aug. 2010. NASA/TM-2011-216951. 


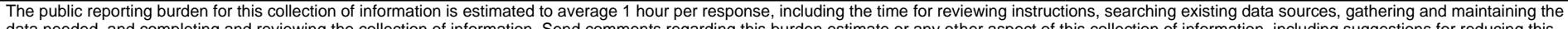

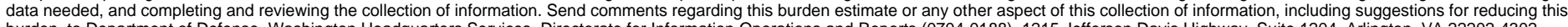

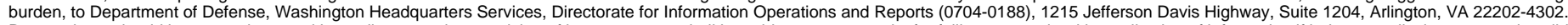

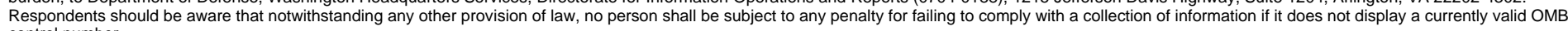

PLEASE DO NOT RETURN YOUR FORM TO THE ABOVE ADDRESS.

\begin{tabular}{l|l|l}
\hline $\begin{array}{l}\text { 1. REPORT DATE (DD-MM-YYYY) } \\
01-10-2011\end{array}$ & $\begin{array}{l}\text { 2. REPORT TYPE } \\
\text { Technical Memorandum }\end{array}$ & 3. DATES COVERED (FrOm - To) \\
\hline
\end{tabular}

4. TITLE AND SUBTITLE

Development and Implementation of a Model-Driven Envelope Protection System for In-

Flight Ice Contamination

5a. CONTRACT NUMBER

5b. GRANT NUMBER

5c. PROGRAM ELEMENT NUMBER

6. AUTHOR(S)

Gingras, David, R.; Barnhart, Billy, P.; Ranaudo, Richard, J.; Martos, Borja; Ratvasky,

Thomas, P.; Morelli, Eugene 5d. PROJECT NUMBER

5e. TASK NUMBER

5f. WORK UNIT NUMBER

WBS 645846.02.07.11.02

7. PERFORMING ORGANIZATION NAME(S) AND ADDRESS(ES)

National Aeronautics and Space Administration

John H. Glenn Research Center at Lewis Field

Cleveland, Ohio 44135-3191

9. SPONSORING/MONITORING AGENCY NAME(S) AND ADDRESS(ES)

National Aeronautics and Space Administration

Washington, DC 20546-0001
8. PERFORMING ORGANIZATION REPORT NUMBER

E-17565
10. SPONSORING/MONITOR'S ACRONYM(S)

NASA

11. SPONSORING/MONITORING REPORT NUMBER

NASA/TM-2011-216960

\section{DISTRIBUTION/AVAILABILITY STATEMENT}

Unclassified-Unlimited

Subject Categories: 05 and 08

Available electronically at http://www.sti.nasa.gov

This publication is available from the NASA Center for AeroSpace Information, 443-757-5802

\section{SUPPLEMENTARY NOTES}

\section{ABSTRACT}

Fatal loss-of-control (LOC) accidents have been directly related to in-flight airframe icing. The prototype system presented in this paper directly addresses the need for real-time onboard envelope protection in icing conditions. The combinations of a-priori information and realtime aerodynamic estimations are shown to provide sufficient input for determining safe limits of the flight envelope during in-flight icing encounters. The Icing Contamination Envelope Protection (ICEPro) system has been designed and implemented to identify degradations in airplane performance and flying qualities resulting from ice contamination and provide safe flight-envelope cues to the pilot. Components of ICEPro are described and results from preliminary tests are presented.

15. SUBJECT TERMS

Aircraft icing; Flight safety; Flight simulation training; Ice protection system; Parameter identification

\begin{tabular}{|c|c|c|c|c|c|}
\hline \multicolumn{3}{|c|}{ 16. SECURITY CLASSIFICATION OF: } & \multirow{2}{*}{$\begin{array}{l}\text { 17. LIMITATION OF } \\
\text { ABSTRACT } \\
\text { UU }\end{array}$} & \multirow{2}{*}{$\begin{array}{l}\text { 18. NUMBER } \\
\text { OF } \\
\text { PAGES } \\
25\end{array}$} & $\begin{array}{l}\text { 19a. NAME OF RESPONSIBLE PERSON } \\
\text { STI Help Desk (email:help@sti.nasa.gov) } \\
\text { 19b. TELEPHONE NUMBER (include area code) }\end{array}$ \\
\hline $\begin{array}{l}\text { a. REPORT } \\
U\end{array}$ & $\begin{array}{l}\text { b. ABSTRACT } \\
U\end{array}$ & $\begin{array}{l}\text { C. THIS } \\
\text { PAGE }\end{array}$ & & & $\begin{array}{l}\text { 19b. TELEPHONE NUMBER (include area code) } \\
443-757-5802\end{array}$ \\
\hline
\end{tabular}



